\title{
Optimization Testbed CometBoards Extended Into Stochastic Domain
}

Surya N. Patnaik

Ohio Aerospace Institute, Brook Park, Ohio

Shantaram S. Pai and Rula M. Coroneos

Glenn Research Center, Cleveland, Ohio 


\section{NASA STI Program . . . in Profile}

Since its founding, NASA has been dedicated to the advancement of aeronautics and space science. The NASA Scientific and Technical Information (STI) program plays a key part in helping NASA maintain this important role.

The NASA STI Program operates under the auspices of the Agency Chief Information Officer. It collects, organizes, provides for archiving, and disseminates NASA's STI. The NASA STI program provides access to the NASA Aeronautics and Space Database and its public interface, the NASA Technical Reports Server, thus providing one of the largest collections of aeronautical and space science STI in the world. Results are published in both non-NASA channels and by NASA in the NASA STI Report Series, which includes the following report types:

- TECHNICAL PUBLICATION. Reports of completed research or a major significant phase of research that present the results of NASA programs and include extensive data or theoretical analysis. Includes compilations of significant scientific and technical data and information deemed to be of continuing reference value. NASA counterpart of peer-reviewed formal professional papers but has less stringent limitations on manuscript length and extent of graphic presentations.

- TECHNICAL MEMORANDUM. Scientific and technical findings that are preliminary or of specialized interest, e.g., quick release reports, working papers, and bibliographies that contain minimal annotation. Does not contain extensive analysis.

- CONTRACTOR REPORT. Scientific and technical findings by NASA-sponsored contractors and grantees.
- CONFERENCE PUBLICATION. Collected papers from scientific and technical conferences, symposia, seminars, or other meetings sponsored or cosponsored by NASA.

- SPECIAL PUBLICATION. Scientific, technical, or historical information from NASA programs, projects, and missions, often concerned with subjects having substantial public interest.

- TECHNICAL TRANSLATION. Englishlanguage translations of foreign scientific and technical material pertinent to NASA's mission.

Specialized services also include creating custom thesauri, building customized databases, organizing and publishing research results.

For more information about the NASA STI program, see the following:

- Access the NASA STI program home page at http://www.sti.nasa.gov

- E-mail your question via the Internet to help@ sti.nasa.gov

- Fax your question to the NASA STI Help Desk at 443-757-5803

- Telephone the NASA STI Help Desk at 443-757-5802

- Write to: NASA Center for AeroSpace Information (CASI) 7115 Standard Drive Hanover, MD 21076-1320 
NASA/TM-2010-215820

\section{Optimization Testbed CometBoards Extended Into Stochastic Domain}

Surya N. Patnaik

Ohio Aerospace Institute, Brook Park, Ohio

Shantaram S. Pai and Rula M. Coroneos

Glenn Research Center, Cleveland, Ohio

Prepared for the

50th Structures, Structural Dynamics, and Materials Conference

sponsored by the AIAA, ASME, ASCE, AHS, and ASC

Palm Springs, California, May 4-7, 2009

National Aeronautics and

Space Administration

Glenn Research Center

Cleveland, Ohio 44135 
This report contains preliminary findings, subject to revision as analysis proceeds.

Trade names and trademarks are used in this report for identification only. Their usage does not constitute an official endorsement, either expressed or implied, by the National Aeronautics and Space Administration.

This work was sponsored by the Fundamental Aeronautics Program at the NASA Glenn Research Center.

Level of Review: This material has been technically reviewed by technical management.

Available from

NASA Center for Aerospace Information 7115 Standard Drive

Hanover, MD 21076-1320
National Technical Information Service 5285 Port Royal Road Springfield, VA 22161

Available electronically at http://gltrs.grc.nasa.gov 


\title{
Optimization Testbed CometBoards Extended Into Stochastic Domain
}

\author{
Surya N. Patnaik \\ Ohio Aerospace Institute \\ Brook Park, Ohio 44142-1068 \\ Shantaram S. Pai and Rula M. Coroneos \\ National Aeronautics and Space Administration \\ Glenn Research Center \\ Cleveland, Ohio 44135-3191
}

\begin{abstract}
COMparative Evaluation Testbed of Optimization and Analysis Routines for the Design of Structures (CometBoards) is a multidisciplinary design optimization software. It was originally developed for deterministic calculation. It has now been extended into the stochastic domain for structural design problems. For deterministic problems, CometBoards is introduced through its subproblem solution strategy as well as the approximation concept in optimization. In the stochastic domain, a design is formulated as a function of the risk or reliability. Optimum solution including the weight of a structure, is also obtained as a function of reliability. Weight versus reliability traced out an inverted-S-shaped graph. The center of the graph corresponded to a 50 percent probability of success, or one failure in two samples. A heavy design with weight approaching infinity could be produced for a near-zero rate of failure that corresponded to unity for reliability. Weight can be reduced to a small value for the most failure-prone design with a compromised reliability approaching zero. The stochastic design optimization (SDO) capability for an industrial problem was obtained by combining three codes: MSC/Nastran code was the deterministic analysis tool, fast probabilistic integrator, or the FPI module of the NESSUS software, was the probabilistic calculator, and CometBoards became the optimizer. The SDO capability requires a finite element structural model, a material model, a load model, and a design model. The stochastic optimization concept is illustrated considering an academic example and a real-life airframe component made of metallic and composite materials.
\end{abstract}

\section{Introduction}

Optimization research at NASA Glenn Research Center has addressed structural design, airliner synthesis, as well as the performance improvement of jet engines. The accumulated multidisciplinary design activity is collected under a testbed that is acronymed "CometBoards" (COMparative Evaluation Testbed of Optimization and Analysis Routines for the Design of Structures) (Ref. 1). The code formulates design as a nonlinear mathematical programming problem and solves it. Problem solution can use any one of the dozen optimization algorithms or the cascade strategy (Ref. 2). An approximation module (Ref. 3) with neural network and regression methods, available in CometBoards, can be used to reduce the number of calculations. The deterministic version of CometBoards can accommodate several different disciplines, each of which can be further divided into subproblems. Thus, the design tool can optimize a system that can be defined in terms of about 100 subproblems. Alternatively, the CometBoards testbed can be used to examine the optimality of a small portion of a larger design problem by an appropriate specification of input data. CometBoards has been successfully applied to structural design of air-breathing propulsion engine and components of Space Station (Ref. 4), airliner synthesis (Ref. 5), as well as performance optimization of jet engines (Ref. 6). 
CometBoards has been extended into the stochastic domain for structural design optimization. The code can be used to study the consequence of scatter in the optimum design solution. The scatter can be in load, in strength and modulus of a material, or in design parameters, like depth and thickness of a beam, etc. Such parameters can be modeled as random variables with probability distribution functions that are defined in terms of mean values and standard deviations. Consequently, response of a structure consisting of stress, strain, displacement, and frequency become random parameters with mean values and standard deviations. The cumulative distribution concept can be utilized to estimate the value of a response parameter for a specified level of probability. For example, the value of von Mises stress at a location in a structure can be estimated to be less than $15 \mathrm{ksi}$ for a 25 -percent probability of success or reliability ( $p=$ $0.25)$. The value can increase to less than $25 \mathrm{ksi}$ for a 75 -percent reliability $(p=0.75)$. The concept illustrated for stress can be extended to other failure modes or design constraints, which become a function of reliability. In stochastic methodology, a structure can be designed for a specified reliability between 0 and 1 . High reliability can lead to a heavier design. The design is likely to be lighter when reliability is compromised. In other words, the weight of a structure becomes a function of the reliability. It would be shown that reliability versus weight traced out an inverted-S-shaped graph.

Reliability-based design optimization requires a probabilistic analysis tool. Several such tools are discussed in References 7 and 8. Here, the fast probabilistic integrator (FPI) module of the NESSUS code (Ref. 9) is used for probabilistic calculation for industrial-strength problems. A quadratic perturbation method (Ref. 7) is used for the academic examples. The probabilistic response is used to formulate the stochastic design problem. It is solved using the optimization testbed CometBoards. The probabilistic analysis and design concepts are illustrated for an academic example and for an industrial-strength airframe wingtip structure made of metallic and composite materials. The later is a Boeing Company. proprietary structural component and only a small amount of information can be published. The subject matter of the paper is presented in five subsequent sections. An outline to the testbed CometBoards is given in Section II. Probabilistic analysis is covered in Section III. Deterministic optimization is discussed in Section IV, followed by stochastic design in Section V, and conclusions in Section VI.

\section{Design Testbed CometBoards}

The testbed CometBoards was originally developed to evaluate the performance of different mathematical programming algorithms and structural analysis methods while solving an optimization problem. The acronym "CometBoards" stands for COMparative Evaluation Testbed of Optimization and Analysis Routines for the Design of Structures. The scope of the testbed has been expanded to include the design of structures, synthesis of airliner, and the operation optimization of air-breathing propulsion engines. CometBoards has several different analysis methods and one dozen optimization algorithms. It has a modular organization with a soft coupling feature that allows quick integration of new or usersupplied analyzers and optimizers without changing the source code. The CometBoards code reads information from data files; formulates design as a sequence of subproblems; and generates the optimum solution.

CometBoards can be used to solve a large problem, definable through multiple disciplines, each of which can be further broken down into subproblems. Alternatively, it can improve an existing system by optimizing a small portion of a large problem. Other unique features of CometBoards include design variable formulation, constraint formulation, subproblem solution strategy, global scaling technique, analysis approximation through neural network and linear regression method, use of sequential and parallel computational platforms, and so forth. The special features and unique strengths of CometBoards assist convergence and reduces the amount of central processing unit (CPU) time required to solve difficult optimization problems of the aerospace industry.

CometBoards has been successfully used to solve the structural design of the International Space Station components, the design of the nozzle components of an air-breathing engine, airframe and engine synthesis for subsonic and supersonic airliner, mixed flow turbofan engine, waverotor-topped engine, and 
so forth. The modular organization of CometBoards is depicted in Figure 1. A brief outline is included for some of its modules.

Scaling and constraint formulation: A multidisciplinary design problem can have a distorted design space because its variables and constraints can vary over a wide range. For example, an engine thrust design variable, which is measured in kilopounds, is immensely different from its bypass ratio, which is a small number. Likewise, the landing velocity of an airliner measured in knots and landing or takeoff field lengths measured in units of thousands of feet differ both in magnitude and in units of measure. This module provides a scheme to reduce the distortion by scaling the design variables, the objective function, and the constraints such that their relative magnitudes during optimization calculations are around unity. The constraints are reformulated to alleviate redundancy and reduce their number (Ref. 10) without affecting the problem definition. The cascade algorithm employs more than one optimizer to solve a complex design problem when an individual mathematical programming method encounters difficulty (Ref. 11).

The module "Analyzers - Structure, Aircraft, Engine-Neural networks and Regression approximations" houses three different types of analysis methods. For structural analysis the methods available are COSMIC NASTRAN (Ref. 12), MSC/NASTRAN (Ref. 13), MHOST (Ref. 14), Analyze/Danalyze codes (Ref. 15), and IFM/Analyzers (Ref. 16). Aircraft analysis can use the FLOPS code (Ref. 17). The NEPP (NASA Engine Performance Program) code (Ref. 18) is employed for airbreathing propulsion engine cycle analysis. Neural network and regression techniques can be employed to approximate an analysis method. A solution of a problem can utilize any one of three analyzers: (1) an original analyzer, for example, the FLOPS code, or one of the two derived analyzers based on (2) a neural network model or (3) a linear regression approximation.

The module "Engine operations" in Figure 1 refers to the performance optimization of air-breathing propulsion engines for multiple operation points. "Aircraft synthesis" refers to the airframe and engine integration for subsonic and supersonic airliners.

The module "Structural design—Subproblem strategy and Parallel computational environment" refers to design of structures through regular optimization or using a subproblem strategy. This strategy is available in sequential and parallel computational environments. "Multiple disciplines" refers to the solution of a problem, which is defined through different disciplines. CometBoards can accommodate several disciplines each of which can be further divided into subproblems. Subproblem strategy is an attempt to alleviate convergence difficulties that can be encountered during the solution of a large optimization problem. In this strategy the large problem is replaced by a sequence of overlapping modest subproblems. The solution to the large problem is obtained by repeating the solution to the set of subproblems until convergence is achieved.

CometBoards has been extended into the stochastic domain. The stochastic design optimization (SDO) capability is obtained by combining three codes:

(1) The MSC/Nastran code is the deterministic analysis tool.

(2) The FPI module of the NESSUS software is the probabilistic calculator.

(3) The testbed CometBoards becomes the optimizer.

The SDO capability requires four models: a finite element structural model, a material model, a load model, and a design model. In the module "Problem formulation and solution," information is read from data files, the design is cast as a sequence of optimization subproblems, and the solution is obtained. The CometBoards testbed is written in the Fortran 77 language except for the neural network algorithm, which is written in the $\mathrm{C}++$ language. The testbed is available in the Unix operating system on workstations. 


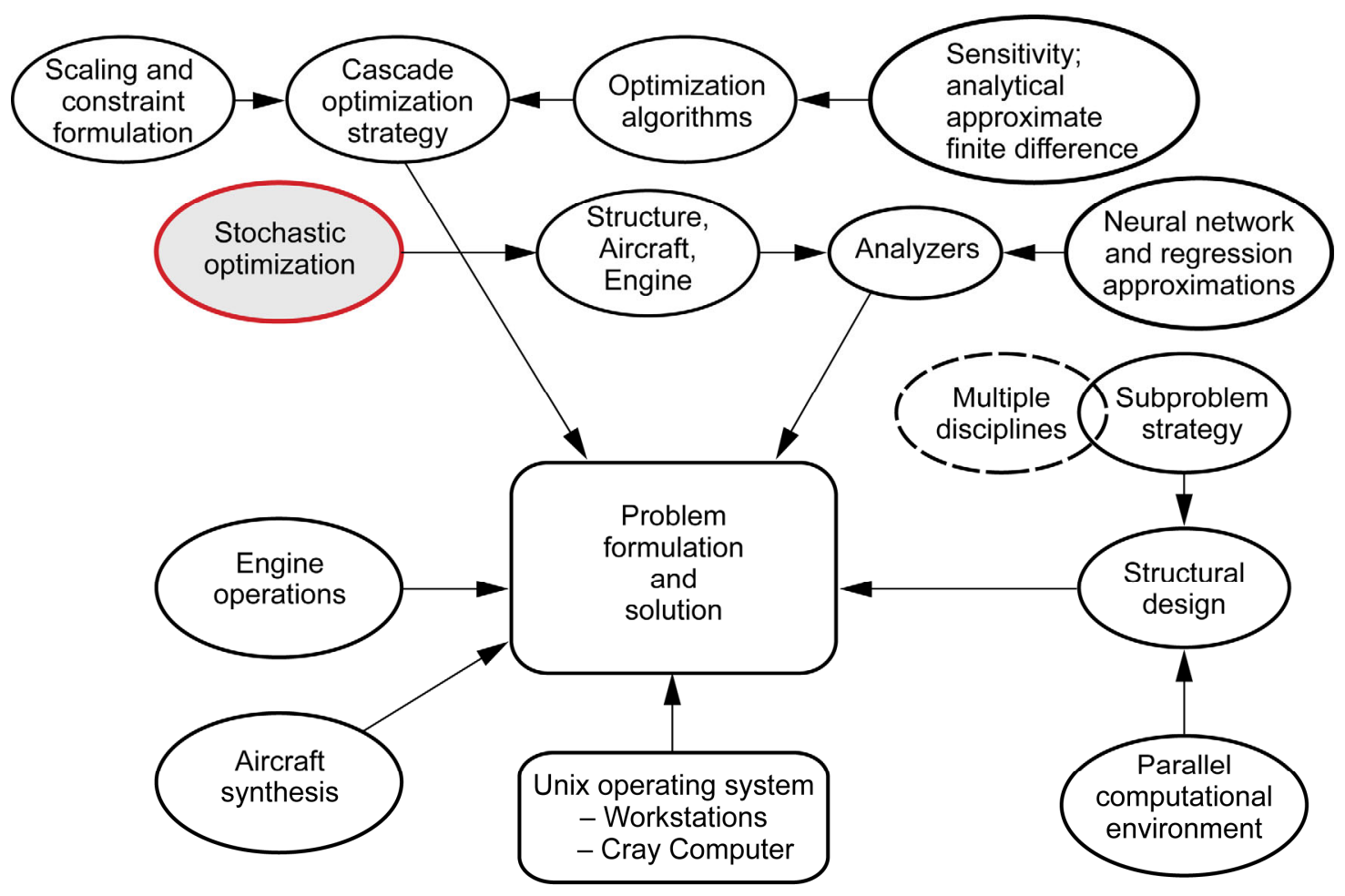

Figure 1.-Organization of optimization testbed CometBoards.

\section{Probabilistic Structural Analysis}

Popular probabilistic analysis formulations included Monte Carlo simulation, sampling and stratified sampling techniques, the Latin hypercube technique, response surface method, and others. Monte Carlo simulation is a powerful numerical approach, but it is repetitive and computationally expensive.

Numerical integration, second-moment analysis, and stochastic finite element methods are also available. The perturbation method has been used extensively in developing the stochastic finite element method because of its simplicity, efficiency, and versatility. In this paper, for academic problems, a quadratic perturbation technique is employed to calculate the mean value and the covariance matrix in closed form for stress and displacement. For an industrial problem, fast probability integration is used. Stochastic response via perturbation method was compared with other probabilistic formulations considering the example of the three-bar truss shown in Figure 2 with 10 random variables for the material properties, load, and sizing design parameters.

A summary of response calculated by the four methods is depicted in Table 1 . Two different computers were used in the calculations shown in Table 1. A Dell Inspiron desktop with four CPUs and a 3.2-GHz processor was used to obtain most of the results. The FPI code shown in the last column was run in a very fast Red Hat Linux dual-CPU workstation with a 32-GHz processor. The four methods compared were

(1) Perturbation method (PM)

(2) Direct Monte Carlo simulation (DMCS)

(3) Latin hypercube simulation (LHS)

(4) Fast probabilistic integration (FPI) of the NESSUS code 


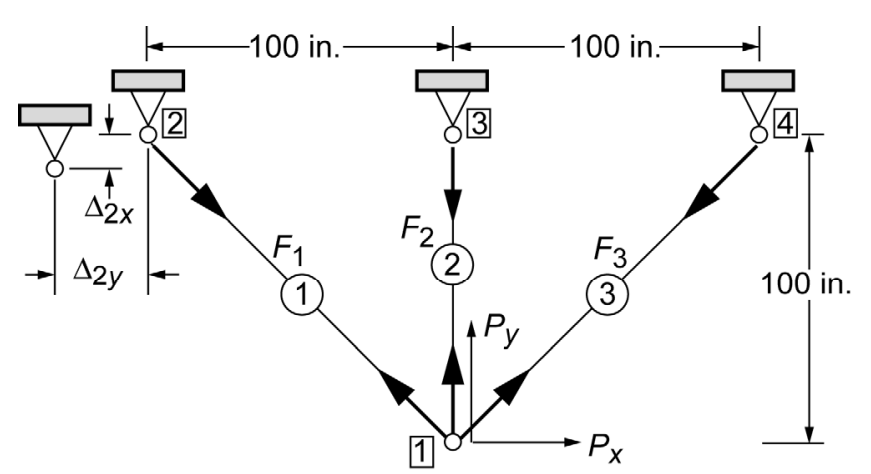

Figure 2.- Stochastic analysis for a three-bar truss.

TABLE 1.-PROBABILISTIC RESPONSE COMPARED FOR THREE-BAR TRUSS

\begin{tabular}{|c|c|c|c|c|c|c|c|c|}
\hline \multirow[t]{2}{*}{ Parameter } & \multicolumn{2}{|c|}{$\begin{array}{l}\text { Perturbation method } \\
\text { (PM) }\end{array}$} & \multicolumn{2}{|c|}{$\begin{array}{c}\text { Direct Monte Carlo } \\
\text { simulation } \\
\text { (DMCS) }\end{array}$} & \multicolumn{2}{|c|}{$\begin{array}{c}\text { Latin hypercube } \\
\text { simulation } \\
\text { (LHS) }\end{array}$} & \multicolumn{2}{|c|}{$\begin{array}{l}\text { Fast probability } \\
\text { integrator } \\
(\mathrm{FPI})\end{array}$} \\
\hline & $\begin{array}{l}\text { Mean } \\
\text { value }\end{array}$ & $\begin{array}{l}\text { Standard } \\
\text { deviation }\end{array}$ & $\begin{array}{l}\text { Mean } \\
\text { value }\end{array}$ & $\begin{array}{l}\text { Standard } \\
\text { deviation }\end{array}$ & $\begin{array}{l}\text { Mean } \\
\text { value }\end{array}$ & $\begin{array}{l}\text { Standard } \\
\text { deviation }\end{array}$ & $\begin{array}{l}\text { Mean } \\
\text { value }\end{array}$ & $\begin{array}{l}\text { Standard } \\
\text { deviation }\end{array}$ \\
\hline Force: $\left\{\begin{array}{l}F_{1} \\
F_{2} \\
F_{3}\end{array}\right\}^{\text {kip }}$ & $\left\{\begin{array}{l}62.77 \\
61.24 \\
-7.95\end{array}\right\}$ & $\left\{\begin{array}{l}4.39 \\
4.35 \\
4.67\end{array}\right\}$ & $\left\{\begin{array}{l}62.77 \\
61.27 \\
-7.93\end{array}\right\}$ & $\left\{\begin{array}{l}4.39 \\
4.35 \\
4.67\end{array}\right\}$ & $\left\{\begin{array}{l}62.76 \\
61.25 \\
-7.96\end{array}\right\}$ & $\left\{\begin{array}{l}4.39 \\
4.35 \\
4.67\end{array}\right\}$ & $\left\{\begin{array}{l}62.78 \\
61.21 \\
-7.93\end{array}\right\}$ & $\left\{\begin{array}{l}4.39 \\
4.35 \\
4.67\end{array}\right\}$ \\
\hline Stress : $\left\{\begin{array}{l}\sigma_{1} \\
\sigma_{2} \\
\sigma_{3}\end{array}\right\}^{\mathrm{ksi}}$ & $\left\{\begin{array}{c}63.29 \\
61.70 \\
-3.98\end{array}\right\}$ & $\left\{\begin{array}{l}6.71 \\
6.20 \\
2.34\end{array}\right\}$ & $\left\{\begin{array}{r}63.16 \\
61.58 \\
-3.97\end{array}\right\}$ & $\left\{\begin{array}{l}5.89 \\
5.42 \\
2.79\end{array}\right\}$ & $\left\{\begin{array}{l}63.15 \\
61.57 \\
-3.99\end{array}\right\}$ & $\left\{\begin{array}{l}5.77 \\
5.38 \\
2.75\end{array}\right\}$ & $\left\{\begin{array}{r}62.78 \\
61.21 \\
-3.96\end{array}\right\}$ & $\left\{\begin{array}{l}6.34 \\
6.03 \\
2.69\end{array}\right\}$ \\
\hline Displacement : $\left\{\begin{array}{l}u \\
v\end{array}\right\}^{\text {in. }}$ & $\left\{\begin{array}{r}0.20 \\
-0.24\end{array}\right\}$ & $\left\{\begin{array}{l}0.004 \\
0.003\end{array}\right\}$ & $\left\{\begin{array}{r}0.20 \\
-0.24\end{array}\right\}$ & $\left\{\begin{array}{l}0.004 \\
0.003\end{array}\right\}$ & $\left\{\begin{array}{r}0.20 \\
-0.24\end{array}\right\}$ & $\left.\begin{array}{l}0.004 \\
0.003\end{array}\right\}$ & $\left\{\begin{array}{r}0.20 \\
-0.24\end{array}\right.$ & $\left\{\begin{array}{l}0.004 \\
0.003\end{array}\right\}$ \\
\hline \multicolumn{9}{|c|}{ Computation time } \\
\hline $\begin{array}{l}\text { CPU seconds } \\
\text { Normalized time }\end{array}$ & & & & & & & & \\
\hline
\end{tabular}

The stiffness method as implemented in the ANSYS code (Ref. 19) was used in the DMCS and in the LHS methods. Response was calculated via the primal and the dual integrated force methods (IFM and IFMD, respectively) in the perturbation and fast probability integration techniques. Both IFM and IFMD yield identical solutions for deterministic as well as stochastic calculations even though the structure of equations differed, at least in appearance. Response for the three bar forces, stresses, and displacements by the four methods (PM, DCMS, LHS, and FPI) and time to solution (CPU seconds) are depicted in the Table 1. For bar forces the mean values and standard deviations were in good agreement for all four methods: the perturbation method, DMCS, Latin hypercube simulation, and fast probability integrator. The displacements showed an almost perfect match across the four methods. There was a minor deviation among the methods for bar stress. DMCS required 12500 samples for convergence, whereas 1000 samples were sufficient for the Latin hypercube simulation. The time to calculate the response was very small, between 1 to 7 CPU sec by the perturbation method as well as by the fast probability integrator. The calculation time increased many times for the Monte Carlo and Latin hypercube simulations. Monte Carlo simulation required about $4245 \mathrm{sec}$, which corresponded to 606 times that required by the perturbation method. Latin hypercube method took 56 times as long. Overall, the performance was satisfactory for all four methods. The Ph.D. dissertation of Wei (Ref. 8) provides merits and limitations of different probabilistic analysis methods. 


\section{Deterministic Optimization}

Two features of CometBoards pertaining to deterministic optimization are illustrated. These are the subproblem solution strategy and the approximation concepts available in the code.

\section{A. Subproblem Solution Strategy}

Design optimization of a large problem can be attempted through a subproblem strategy to avoid convergence difficulties. The large problem is divided into several modest subproblems as shown in Figure 3(a). Solution to the original problem is obtained iteratively through repeated solutions to the modest subproblems. Adequate coupling (overlap) must be provided between subproblems as shown in Figure 3(a), otherwise, difficulty can be encountered. Subproblem optimization can be carried out in either a sequential or a parallel computational mode on a multiprocessor computer. The subproblem solution strategy for sequential computation, is executed through two major do-loop statements as depicted in Figure 3(b). The basic steps are as follows:

1. Initialize all design variables for the original problem.

2. Define each subproblem and ensure adequate overlap.

3. Define design variables for each subproblem. It must have at least two independent design variables and at least one variable must be common to two subproblems.

4. Formulate subproblem optimization. Its constraint set should include all stress and buckling constraints for the subproblem in question. Frequency and displacement are global constraints and should be common to all the subproblems. Define subproblem merit function or weight. Solve the optimization subproblem.

5. Update the design variables for the entire structure as soon as a subproblem is solved.

6. Execute the inner loop for all subproblems. Convergence or stop criteria for the inner loop need not be very stringent.

7. Repeat the steps; that is, execute the outer loop, also called cycles, until convergence occurs for the entire problem. A tighter convergence or stop criterion can be specified for the outer loop.

The subproblem solution strategy for parallel computation, as shown in Figure 3(c), is quite similar to that for sequential calculations. The difference pertains to simultaneous or parallel solutions to the subproblems in different processors of a computer. Balancing computational loads between the processors requires that the solution complexity of the different subproblems be equal. Each subproblem has to be optimized independently without any exchange of information between subproblems. Design variables are updated only after all subproblems have been solved. Repeat the above steps or execute the outer loop until convergence occurs for the entire problem.

Subproblem solution strategy available in CometBoards is illustrated considering the design of the space shuttle cargo bay support system shown in Figure 4 as an example.

The structure, shown in Figure 4 is made of aluminum with a Young's modulus of $9.9 \times 10^{6} \mathrm{psi}$, a Poisson's ratio of 0.303 , a weight density of $0.098 \mathrm{lb} / \mathrm{in}^{3}{ }^{3}$, and an allowable strength of $30000 \mathrm{psi}$. Critical design loads were generated from a variety of shuttle accelerations and maneuvers (Ref. 20). Loads for the support system were obtained by analyzing a coupled model with 9658 finite elements and 7439 nodes. The support system was designed for minimum weight under stress and displacement constraints. The structural model of the support, which was divided into 4 segments has 132 shell finite elements. The first segment FGHIJK is a closed box composed of 5 plates; it was discretized into 72 shell elements. The second segment FHEC has 36 elements; the third GHE and fourth GHD segments have 12 elements each. The 5 connecting frame members were treated as passive variables during design, but for analysis they were discretized using 20 beam elements. For the purpose of optimization, the shell thicknesses were considered the design variables. Through design variable formulation, the nodal thicknesses of all elements within a segment were grouped to obtain a single independent design variable. The support system for parallel computation was divided into three subproblems: Subproblem 1 consisted 
of segments 1 and 2; subproblem 2 contained segments 2 and 3; and subproblems 3 and 4 contained segments 3 and 4, respectively. For sequential computation, a fourth subproblem consisting of segments 4 and 1 was considered to close the inner loop to accelerate the convergence process. For parallel computation, the design variables for the entire structure were updated only after all subproblems were solved; therefore, it was not necessary to include subproblem 4.

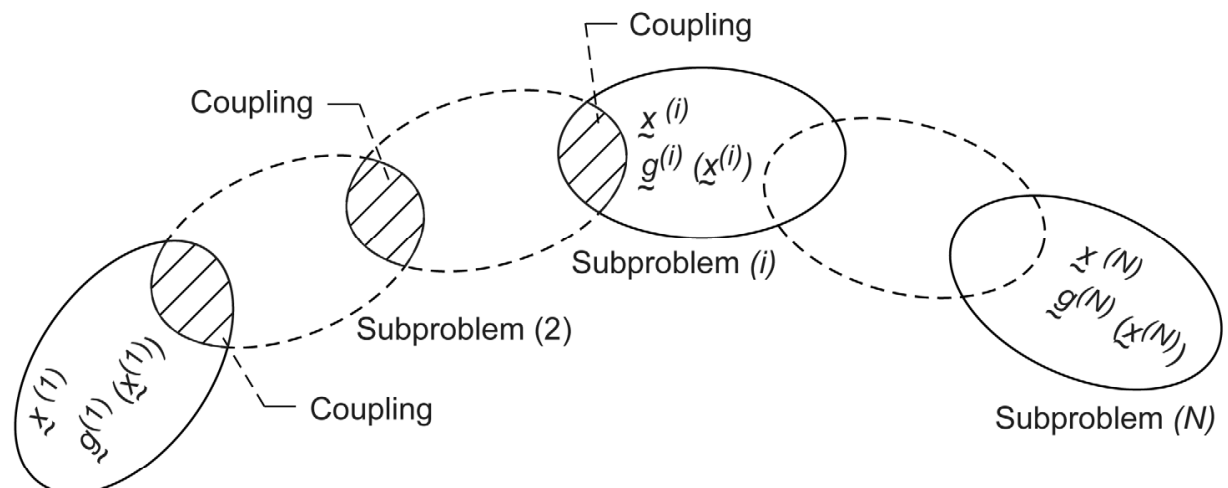

(a)

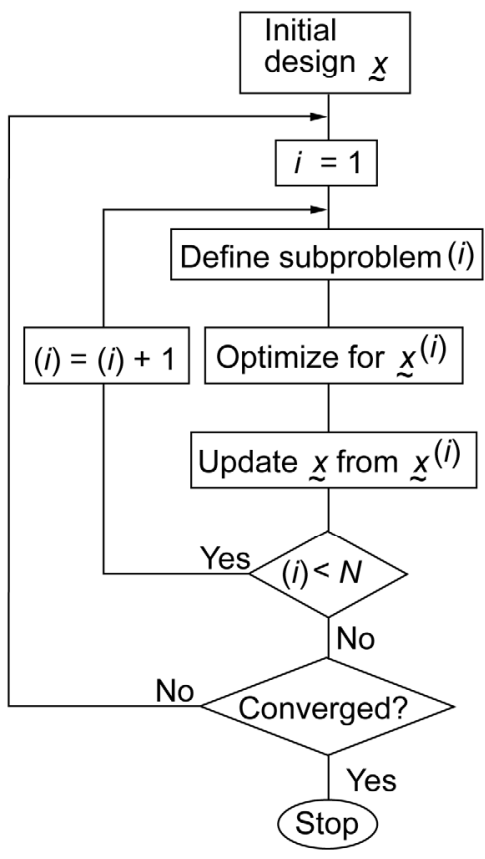

(b)

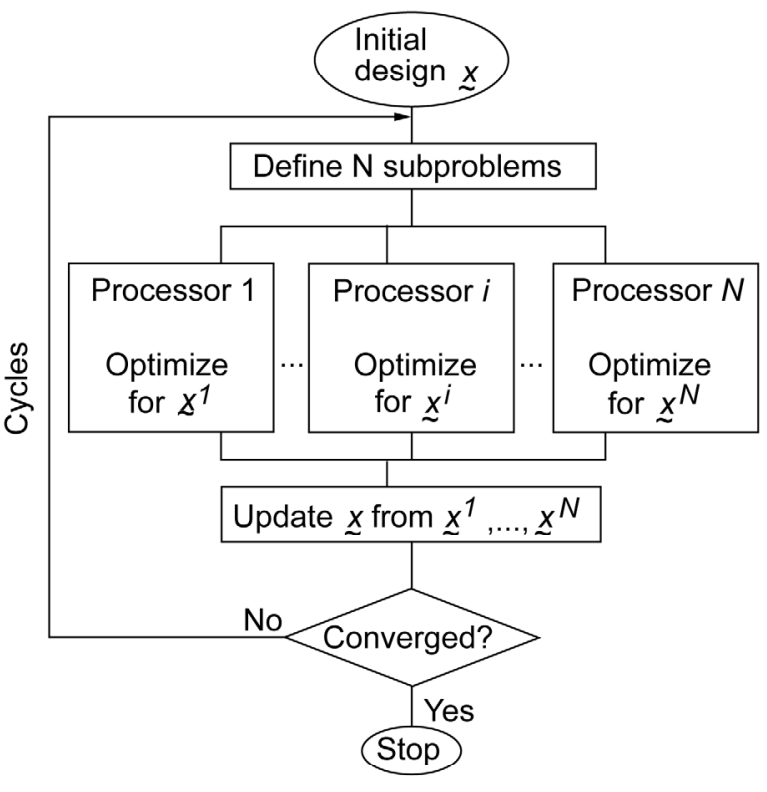

(c)

Figure 3.-Subproblem solution strategy. (a) Subproblem coupling. (b) Sequential calculations. (c) Parallel calculations. 


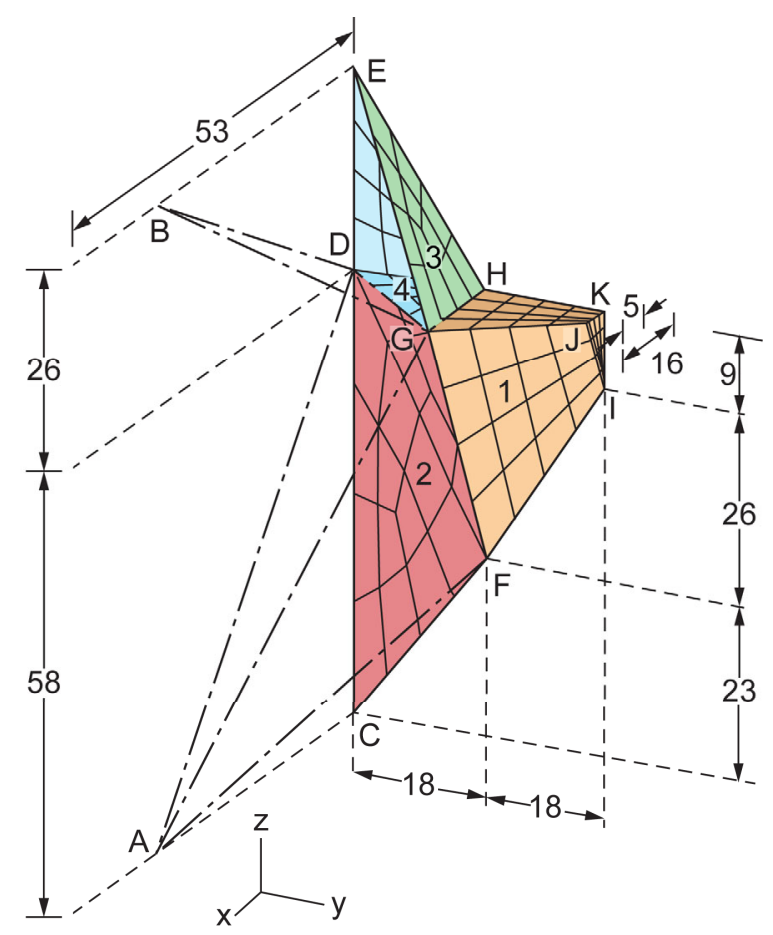

Figure 4.-Cargo-bay support system of the International Space Station (dimensions are in inches).

Optimization results for the support system, shown in Table 2 gives the weight of the subproblem after the completion of each outer loop and provides the optimum design and the number of active constraints. For this problem, acceptable convergence was achieved after three executions of the outer loop. Optimum results obtained by parallel and sequential subproblem strategy compared very well with that obtained when the entire structure was optimized as a single unit. Subproblem convergence history is presented in Figure 5. The support system in sequential calculations converged in two cycles; however, three cycles were required for parallel computations. The optimization process reduced the weight by 36 percent from the initial weight of $54.35 \mathrm{lb}$ to the final weight of $34.7 \mathrm{lb}$. The sequential calculation produced two active constraints, while parallel mode as well as regular optimization yielded an additional active constraint.

TABLE 2.-OPTIMUM DESIGN FOR SPACE SHUTTLE CARGO BAY SUPPORT SYSTEM

\begin{tabular}{|c|c|c|c|c|}
\hline Parameter & $\begin{array}{c}\text { Initial variable, } \\
\text { in. }\end{array}$ & \multicolumn{2}{|c|}{ Substructuring } & $\begin{array}{c}\text { No substructuring } \\
\text { (single unit) }\end{array}$ \\
\hline Design variables & Thickness & Sequential & Parallel & \\
\hline 1 & 0.2 & 0.1281 & 0.1277 & 0.1277 \\
2 & 0.2 & 0.1299 & 0.1298 & 0.1299 \\
3 & 0.2 & 0.1765 & 0.1765 & 0.1763 \\
4 & 0.2 & 0.0319 & 0.0264 & 0.0263 \\
\hline Number of active & --- & 2 & 3 & 3 \\
constraints & & & & 34.72 \\
\hline Weight, lb & 54.35 & 34.74 & 34.71 & \\
\hline
\end{tabular}




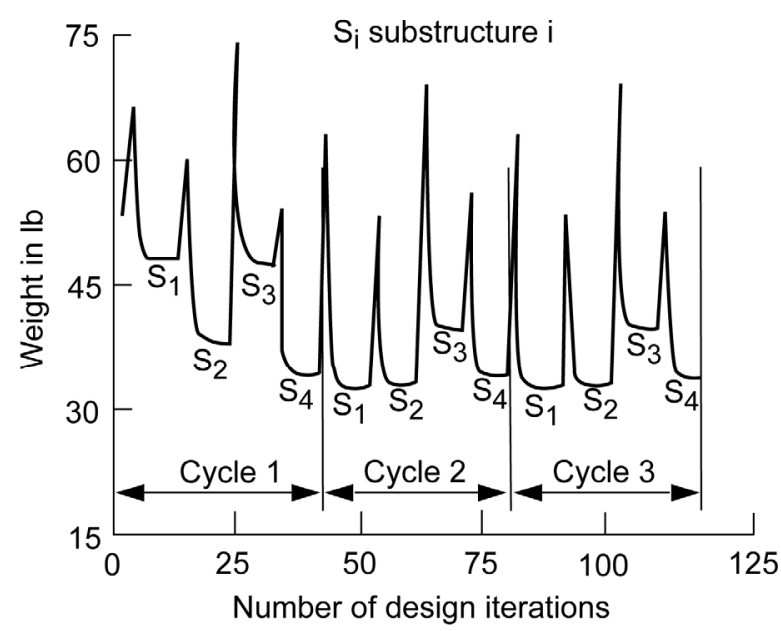

Figure 5.-Subproblem solution for cargo bay support system.

\section{B. Approximation Concepts in CometBoards}

CometBoards has two different types of approximation concepts. The first pertains to a simplification of the design sensitivity. The second is analysis approximation using neural network and regression technique. Both concepts are illustrated.

\section{Simplification of Design Sensitivity}

Design sensitivity is central to most optimization algorithms. Consider a key formula to update the design in a nonlinear programming algorithm. At a $k$ th intermediate iteration.

$$
\{X\}_{k}=\{X\}_{k-1}+\alpha_{k-1}\{S\}_{k-1}
$$

where $\{X\}_{k}$ is the design, $\{S\}_{k}$ is the search direction, and $\alpha$ is the step length.

Design sensitivity is used to calculate the search direction. Algorithms are named after sensitivity, for example, method of steepest descent, conjugate-direction method of Fletcher and Reeves and variable metric method, etc. Different directions traverse different paths to reach the optimum point from an initial design as shown in Figure 6.

An approximation to sensitivity would result in a veering of the path. It will be shown that optimum will be reached following a path that would be generated via an approximation to the sensitivity because there is no uniqueness to the path as shown in Figure 6. Consider a stress constraint, $g(X)$, which is a function of design variables $(X)$. The constraint can be expressed as a product of an explicit function $F(X)$ and an implicit function $R(X)$ as

$$
g(X)=F(X) \cdot R(X)
$$

Its gradient can be written as

$$
\nabla g(x X)=\stackrel{\text { simple-Retain }}{R \nabla F}+\begin{gathered}
\text { calculation-intensive-DROP } \\
F \nabla R
\end{gathered} \approx \begin{gathered}
\text { simple-Retain } \\
R \nabla F
\end{gathered}
$$

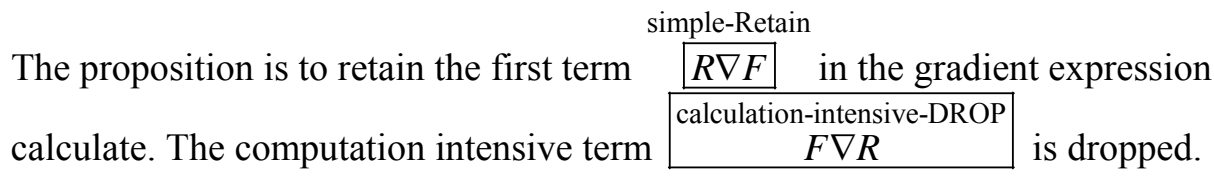




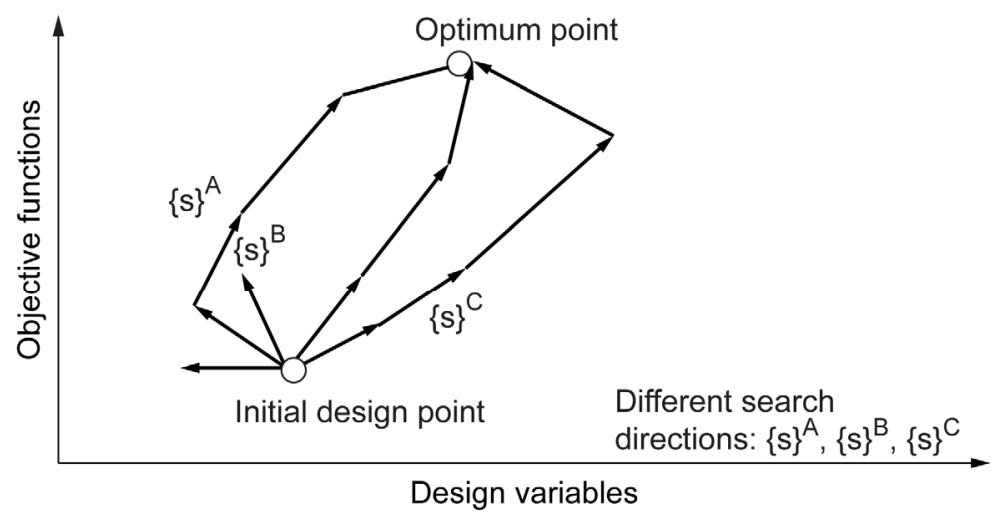

Figure 6.-Illustration of search direction.

Consider a plate flexure problem as an example for structural design optimization. Its thickness $(h)$ is considered as the design variable. It has two principal moments $\left(M_{1}\right.$ and $\left.M_{2}\right)$. The von Mises stress, $\sigma_{j}$, that can be used to define the stress constraint can be written as

$$
\sigma_{j}^{\text {plate }}\left(h_{j}\right)=\left(\frac{6}{h_{i}^{2}}\right) \sqrt{\left(M_{1}^{2}\left(h_{i}\right)+M_{2}^{2}\left(h_{i}\right)-M_{1}\left(h_{i}\right) M_{2}\left(h_{i}\right)\right)_{j}}
$$

The gradient of von Mises stress can be obtained as

$$
\begin{aligned}
\nabla \sigma_{j}^{\text {plate }}\left(h_{j}\right)= & \frac{\text { simple-retain }}{\left(-\frac{12}{h_{i}^{3}}\right) \sqrt{\left(M_{1}^{2}\left(h_{i}\right)+M_{2}^{2}\left(h_{i}\right)-M_{1}\left(h_{i}\right) M_{2}\left(h_{i}\right)\right)_{j}}} \\
& +\left(\frac{6}{h_{i}^{2}}\right) \frac{\partial}{\partial h_{i}} \sqrt{\left(M_{1}^{2}\left(h_{i}\right)+M_{2}^{2}\left(h_{i}\right)-M_{1}\left(h_{i}\right) M_{2}\left(h_{i}\right)\right)_{j}}
\end{aligned}
$$

The gradient is simplified by retaining the first simple term, which can be generated with a trivial amount of calculation as

$$
\nabla \sigma_{j}^{\text {plate }}\left(h_{j}\right)=\sqrt{\left(-\frac{12}{h_{i}^{3}}\right) \sqrt{\left(M_{1}^{2}\left(h_{i}\right)+M_{2}^{2}\left(h_{i}\right)-M_{1}\left(h_{i}\right) M_{2}\left(h_{i}\right)\right)_{j}}}
$$

The term in equation (6) can be arranged along the diagonal of a matrix for a structure made of $\mathrm{n}$-number of plates. The approximate gradient concept is independent of structure type and it can be used in finite element analysis. Likewise, the gradient of displacement can be approximated for a general type of structure. 


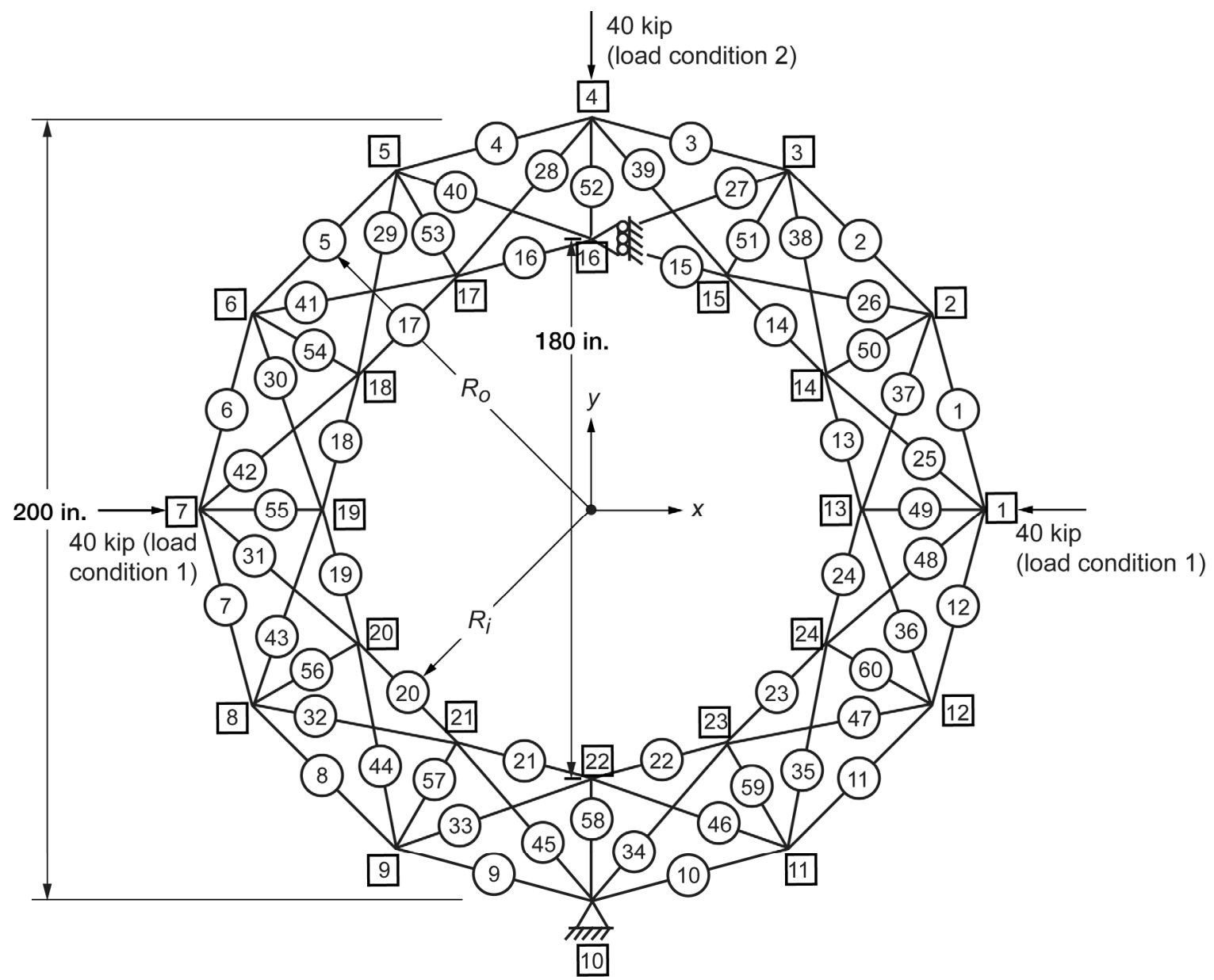

Figure 7.-A 60-bar trussed ring.

\section{Numerical Illustration}

The approximation concept is illustrated for the design optimization of a steel-trussed ring shown in Figure 7. The ring was made of 60 bars and had inner and outer diameters of 180 and $200 \mathrm{in}$., respectively. It was fully restrained at node 10 and free to move only along the y direction at the diametrically opposite node 16 . The ring was subjected to two load conditions. The first load condition consisted of a 40-kip compression along the ring's horizontal diameter, which was applied at nodes 1 and 7. In the second case, a 40-kip load was applied at node 4 to induce compression along the vertical diameter. The 60-bar areas of the truss were grouped to obtain 16 linked design variables. The ring had 60 stress constraints (with a yield strength of $20 \mathrm{ksi}$ ) for each load condition.

The distortions of the ring along the horizontal and vertical diameters were controlled through a 4-in. displacement limitation specified at nodes 1,4 , and 7 for each load condition. The problem had a total of 120 stress and 6 displacement constraints. Optimum solutions generated by two algorithms: SQP or sequential quadratic programming and SUMT or sequential unconstrained minimization technique are given in Table 3. Optimum solution was obtained with closed form or analytical sensitivity as well as approximate sensitivity. Instead of individual parameters the mean, maximum, and minimum values are given for the 16 design variables. Both SQP and SUMT algorithms with approximate as well as the closed-form or analytical sensitivities converged to the same solution of about $800 \mathrm{lb}$ with a 0.25 -percent deviation in the minimum weight. 
TABLE 3.-OPTIMUM SOLUTION FOR THE TRUSSED RING

\begin{tabular}{|c|c|c|c|c|c|c|c|c|}
\hline \multirow[t]{3}{*}{ Method } & \multirow[t]{3}{*}{$\begin{array}{l}\text { Weight, } \\
\text { lb }\end{array}$} & \multicolumn{3}{|c|}{$\begin{array}{c}\text { Design variables, } \\
\text { in. }{ }^{2}\end{array}$} & \multicolumn{2}{|c|}{ Active constraints } & \multirow[t]{3}{*}{$\begin{array}{l}\text { CPU time, } \\
\text { sec }\end{array}$} & \multirow[t]{3}{*}{ Sensitivity } \\
\hline & & \multirow{2}{*}{$\begin{array}{l}\text { Mean } \\
\text { value }\end{array}$} & \multicolumn{2}{|c|}{ Variation } & \multirow[t]{2}{*}{ Stress } & \multirow[t]{2}{*}{ Displacement } & & \\
\hline & & & Min. & Max. & & & & \\
\hline SQP & 799.9 & 3.15 & 2.18 & 4.05 & 28 & 1 & 2.3 & Approximate \\
\hline SUMT & 797.7 & 3.15 & 2.18 & 4.01 & 28 & 1 & 1.3 & Approximate \\
\hline SQP & 799.9 & 3.15 & 2.18 & 4.04 & 28 & 1 & 7.4 & Analytical \\
\hline SUMT & 798.0 & 3.15 & 2.19 & 4.00 & 28 & 1 & 7.1 & Analytical \\
\hline
\end{tabular}

The CPU time to solution was 321 and 318 percent faster for approximate sensitivity with the SQP and SUMT algorithms, respectively. The 16-variable problem had 29 active constraints. The convergence of weight versus CPU time to solution with analytical and approximate sensitivities is depicted in Figure 8 . The optimization was begun with the same initial design. Both methods produced similar optimum solutions. The convergence patterns, with and without approximation, portray undulations that are quite similar. However, the convergence is very rapid with the approximate sensitivity.

\section{E. Jet Engine Design With Regression and Neural Network Approximators}

The NASA Engine Performance Program (NEPP) can encounter difficulty during engine balancing. The deficiency was eliminated through neural network and linear regression methods (see Fig. 9). An approximation-interspersed cascade strategy was used to optimize engine operation over a specified flight envelope. Creating approximate models for engine problem required the management of an enormous amount of numerical data.

To illustrate the benefit from the approximation concepts while keeping numerical calculations within a manageable level, we selected a waverotor-augmented subsonic engine with 10 operating points. The engine was optimized utilizing both neural network and regression approximations, along with a cascade strategy (see Fig. 9). The high bypass-ratio subsonic waverotor-enhanced turbofan engine was made of 16 components on 2 shafts with 21 flow stations. To examine the benefits that accrue from the waverotor enhancement, we optimized the engine by considering several baseline variables to be passive. The objective was to maximize the net engine thrust for two variables: heat added to the waverotor in the range 93700 to $131300 \mathrm{Btu} / \mathrm{sec}$ and waverotor speed in the range 4940 to $7660 \mathrm{rpm}$. Upper and lower bound constraints were specified on a speed ratio for the compressor and fan, along the secondary flow branch in the range 0.7 to 1.01 , corrected speed ratio for the high-pressure compressor along the main flow in the range 0.7 to 1.01 , unmixed temperature in the range 2000 to $3200{ }^{\circ} \mathrm{R}$, surge margin on the compressor along the secondary flow branch in the range 15 to 100 , surge margin on the fan in the range 15 to 100, surge margin on the high-pressure compressor along the main flow in the range 15 to 30 , and pressure ratio for the high-pressure turbine in the range 0.0 to 6.59 .

The cascade solution is depicted in Figure 9 for the sixth operating point. The first leg of the cascade was a quadratic programming algorithm (NLPD). The engine thrust was $73.293 \mathrm{kip}$ but the design was infeasible. The second optimizer, which was a modified method of feasible direction (FD) also yielded an infeasible design. The third leg of cascade was NLPQ and it produced a feasible solution with a 72.989 kip thrust. Both of the approximate methods performed satisfactorily and at about the same level. The engine required the cascade strategy even with the approximate methods. 


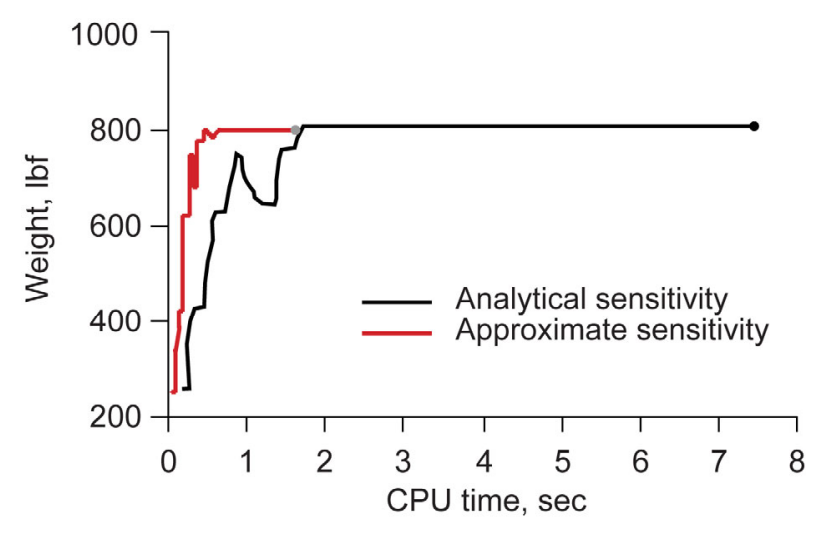

Figure 8.-CPU solution time for SQP algorithm-60-bar trussed ring.

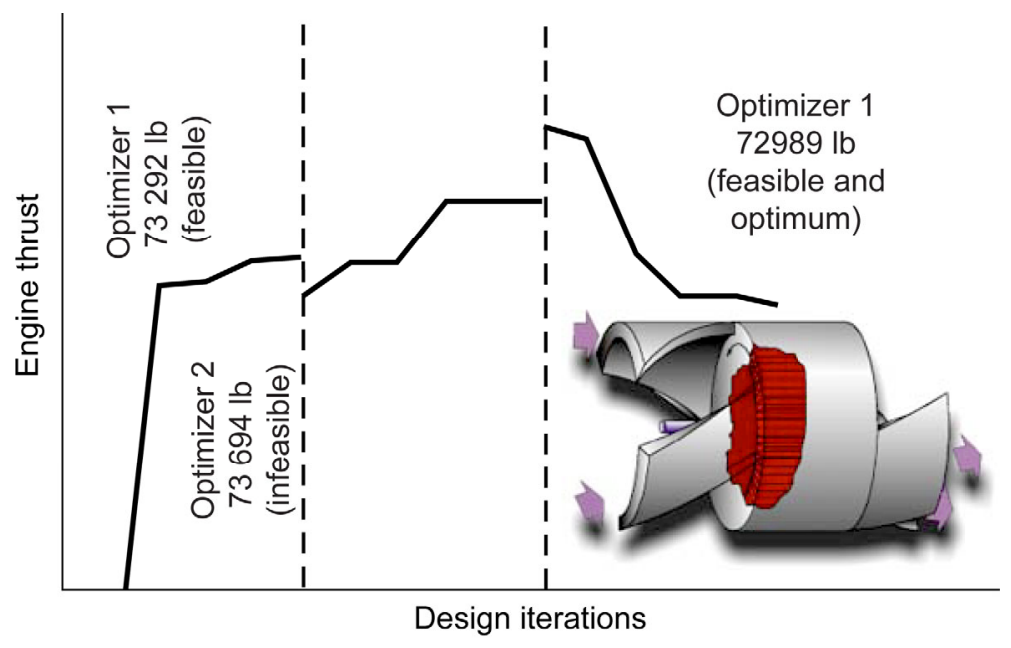

Figure 9.-Cascade solutions for a waverotor-topped engine.

\section{V.Stochastic Design Optimization}

CometBoards has been extended into the stochastic domain. The code formulates stochastic design as a nonlinear mathematical programming problem and solves it. The variables and constraints are treated as random parameters with specified distribution functions that are defined in terms of mean values and standard deviations. A problem can be formulated either to optimize the mean value of an objective function, or to simultaneously optimize the mean value as well as the standard deviation. The former is referred to as stochastic design optimization (SDO) whereas the later became the robust formulation. Robust design may be important for the manufacturing industry but it has little importance to theoretical design calculations. It is discussed in Reference 8 but not repeated here. In SDO, the constraint functions are specified within prescribed random upper and lower bounds for a specified probability of success or reliability between ( 0 and 1$)$. The design accommodated uncertainties in load, strength, and material properties. Design solution and optimum weight became a function of reliability. Optimum weight versus reliability traced out an inverted-S-shaped graph. The center of the inverted-S-shaped graph corresponded to a 50 percent $(p=0.5)$ probability of success. A heavy design with weight approaching infinity could be produced for a near-zero rate of failure that corresponds to unity for reliability. Weight can be reduced to a small value for the most failure-prone design with a reliability that approaches zero $(p=0)$. The SDO capability is obtained by combining three codes. MSC/Nastran is the deterministic analysis tool, the FPI of the NESSUS software is the probabilistic response calculator, and NASA Glenn Research Center's 
testbed CometBoards is the optimizer. The SDO capability requires a finite element model, a material model, a load model, and a design model.

The SDO tool is illustrated through the solutions of two examples. The first example is a web plate of an airframe stabilizer structure. The Boeing 767-400 Extended Range raked wingtip structure made of metals and composite materials is the second example. Examples are proprietary components of the Boeing Company and were provided to us as a courtesy to advance a reliability-based optimization concept for industrial structures. Sufficient information will be given for the web plate example; however, some results will be included for the wingtip problem.

\section{A. Stochastic Design for the Web Plate}

The steel web plate, shown in Figure 10, was part of a composite horizontal stabilizer structure of the Boeing B-777 airliner. It was about 100 in. long, 12 in. wide, and 0.072 in. thick. It was idealized as a planar plate structure. The finite element model had 80 CQUAD4 and 3 CTRIA3 elements and 103 nodes. Load was obtained by projecting the reactive load from the stabilizer into the plane of the web. Load, material properties, and design parameters were considered as random variables.

The mean values were taken equal to their deterministic values with a 10-percent standard deviation. For example, the mean value of Young's modulus was $30000 \mathrm{ksi}$, (which was its deterministic value) with a 10-percent standard deviation of $3000 \mathrm{ksi}$. The stochastic response calculation used three different probabilistic analyses methods. All three methods used MSC/Nastran for deterministic calculation. The FPI module was also used by all three methods. The methods used were

Method 1: This method used the FPI with normal distribution for all variables.

Method 2: A neural network and a regression method were trained for the three design variables. Normal distribution was used with the neural network approximation.

Method 3: This method replaced normal distribution with the Weibull function in method 2. The regression method was used for approximation.

Optimum weights for different probability of failure are given in Table 4. The rate ranged from a vulnerable design with 999 failures in 1000 samples to a reliable design with 1 failure in 1000 samples. There is some deviation in the weight calculated by the three different analyses methods.

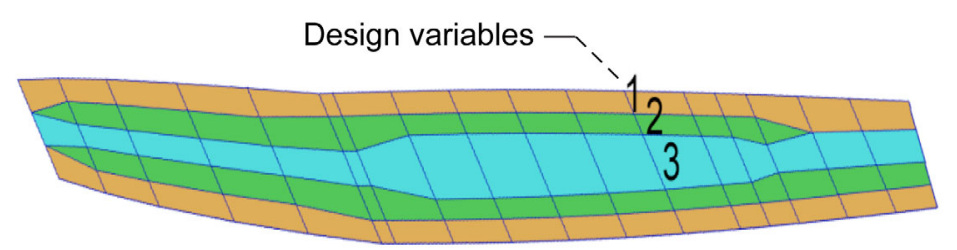

Figure 10.-Design of a web plate of horizontal stabilizer of Boeing B-777. 


\begin{tabular}{|c|c|c|c|c|}
\hline & & \multicolumn{3}{|c|}{ Optimum weight of web plate } \\
\hline $\begin{array}{c}(\mathrm{X}) \\
\text { (X failures in } \\
1000 \text { samples) }\end{array}$ & $\begin{array}{c}\text { Probability level, } \\
p\end{array}$ & $\begin{array}{c}\text { Method } 1 \\
\text { FPI and normal } \\
\text { distribution }\end{array}$ & $\begin{array}{c}\text { Method } 2 \\
\text { Neural network and } \\
\text { normal distribution }\end{array}$ & $\begin{array}{c}\text { Method } 3 \\
\text { Regression method } \\
\text { and Weibull function }\end{array}$ \\
\hline (999) & 0.001 & 1.16 & 1.78 & 1.75 \\
\hline (975) & 0.025 & 1.89 & 2.26 & 2.22 \\
\hline$(900)$ & 0.1 & 2.33 & 2.56 & 2.54 \\
\hline$(700)$ & 0.3 & 2.84 & 2.94 & 2.93 \\
\hline$(500)$ & 0.5 & 3.22 & 3.22 & 3.22 \\
\hline$(300)$ & 0.7 & 3.61 & 3.52 & 3.52 \\
\hline$(100)$ & 0.9 & 4.21 & 3.99 & 3.98 \\
\hline$(25)$ & 0.975 & 4.81 & 4.47 & 4.41 \\
\hline (1) & 0.999 & 5.96 & 5.40 & 5.16 \\
\hline
\end{tabular}

For a 50-percent probability of success, all three methods converged to $3.22 \mathrm{lb}$ for the optimum weight. For a reliable design with 1 failure in 1000 samples, the first FPI method produced weight of 5.96 $\mathrm{lb}$ or about a 10-percent higher weight than that obtained by the neural network technique solution of 5.40 lb. The difference reduced to 5 percent for the regression method with a weight of $5.16 \mathrm{lb}$.

The weight versus probability of success for the web plate given in Table 4 is plotted in Figure 11. Weight increased when reliability exceeded 50 percent. Weight decreased when the reliability was compromised. The weight versus reliability traced out the inverted-S-shaped graph. A design can be selected that depends on the level of risk acceptable to the situation. The inverted-S-shaped graphs were also generated for 20 examples given in Reference 8.

The illustration in Figure 12 provides a simple explanation for the inverted-S shape of the graph. Consider a deterministic design of a structure that was calculated for an allowable stress limitation of $25 \mathrm{ksi}$ and it has a weight of $100 \mathrm{lb}$ (see Fig. 12(a)). The structure is redesigned next for a 50-percent probability of success. Assuming a 1.5 safety factor in applied loads, the stress can be approximated to 17 ksi and the proportioned weight can be approximated as $67 \mathrm{lb}$ (see Fig. 12(b)). Let us consider a reliable design with 1 failure in 100000 samples. The stress value is likely to increase to 24 ksi because of an increase in the corresponding area under the distribution function (see Fig. 12(c)). The weight has to be increased to about $80 \mathrm{lb}$ because of a high value for stress, as shown in Figure 12(c). Consider next a failure-prone design with 90 failures in 100 samples. The stress can be less, like $7 \mathrm{ksi}$, because of a reduced area under the distribution function (see Fig. 12(d)). The weight can be reduced to about $28 \mathrm{lb}$ because of the low stress level. In reliability-based design optimization, weight can become very heavy when reliability approaches unity; likewise, a lightweight design can be obtained when reliability is compromised.

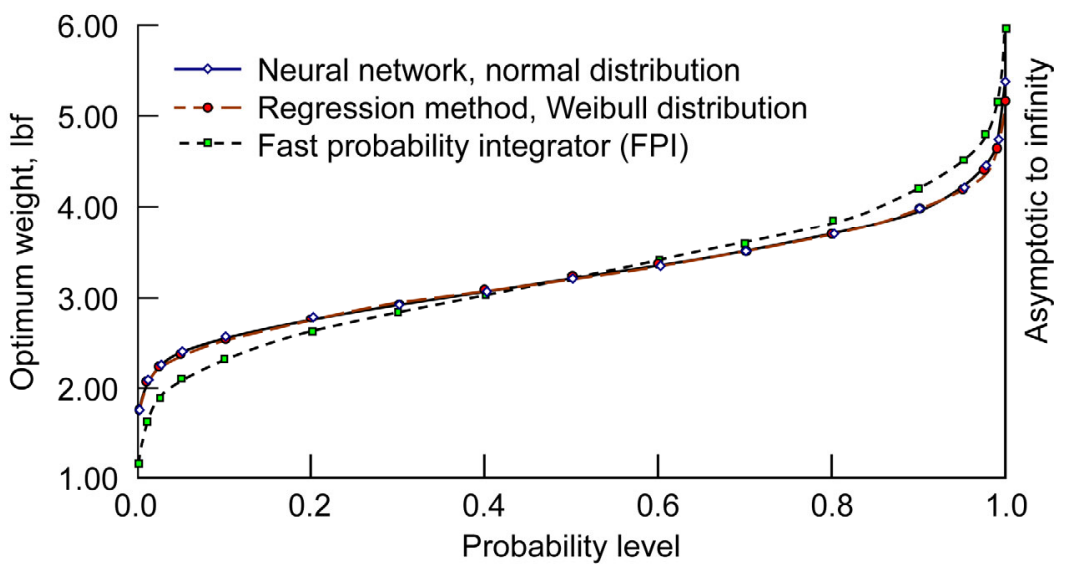

Figure 11.-Inverted-S-shaped graph for optimum weight versus probability level for web plate. 
Assume

stress $\sigma=25 \mathrm{ksi}$

weight $=100 \mathrm{lbf}$

(a) Deterministic design

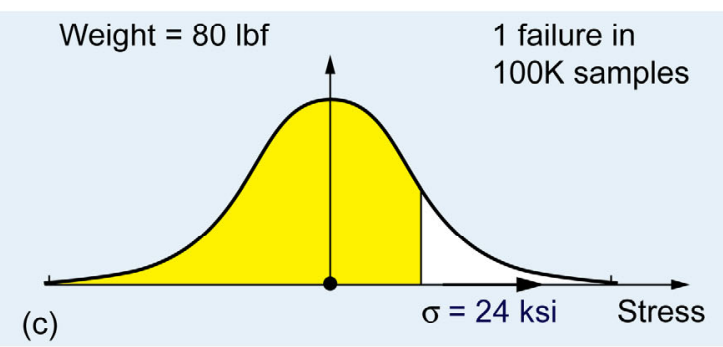

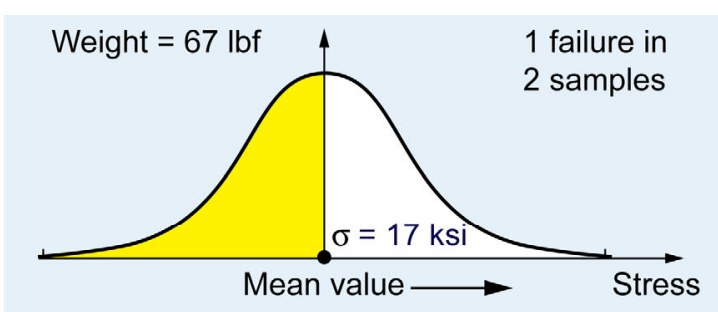

(b) Probabilistic design for $p=0.5$

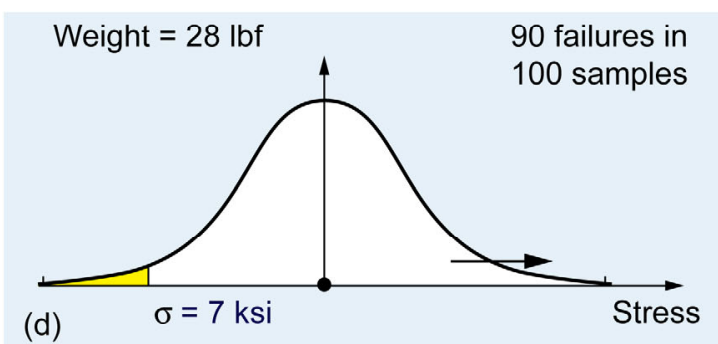

Figure 12.-Basic reliability design concept; a qualitative illustration for induced stress. (a) Deterministic design. (b) Design for mean value. (c) Design for more than mean value. (d) Design for less than mean value.

\section{B. Raked Wingtip Structure}

A reliability-based optimization method was applied to a composite airframe component of the Boeing 767-400 Extended Range airliner. It is referred to as the raked wingtip structure and shown in Figure 13. The presentation becomes cursory because of proprietary nature of the structure. It is fabricated out of components made of metallic and composite materials. The objective was to reduce the weight of the wingtip without changing its geometrical configuration. The problem complexity is increased but the methodology is about the same as that for the web plate. The members of the structure were grouped to obtain a total of 13 active design variables. For constraint formulation, the structure was separated into 203 groups of elements to obtain a total of 203 strain constraints for the panels and the spars. The rod elements were grouped to obtain 16 additional constraints. Three translations and one rotation were also constrained.

The design model had a total of 227 behavior constraints. Constraint can be imposed on principal strain, on a failure theory, or on a strain component. The optimization calculation required continuous running of the code for more than 5 days, but the execution was smooth and eventless. The optimum design exhibited nine active constraints consisting of eight strains and one displacement limitation. The normalized optimum weight was set to 100 units for a reliability of 1 failure in 2 million samples. The weight versus reliability was graphed in Figure 14.

The $\mathrm{x}$-axis represents $\mathrm{N}$ (as in one failure in $\mathrm{N}$ samples) and it begins at $\mathrm{N}=2$, or 50 percent probability of success. This graph represents one-half of the inverted-S-shaped graph because probability less than 50 percent is not included. Sensitivity analysis was performed for the principal strain in an element for deterministic as well as for SDO and depicted in Figure 15. 


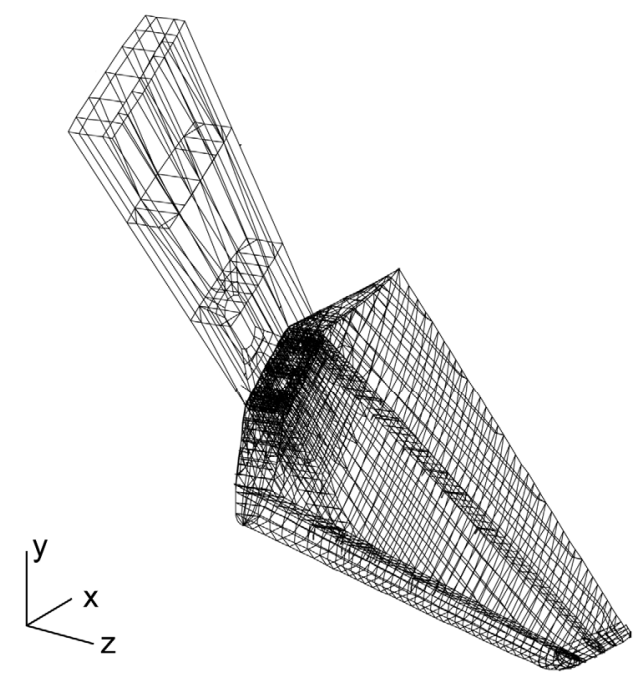

Figure 13.-Model of raked wingtip of Boeing B-767-400 Extended Range airliner.

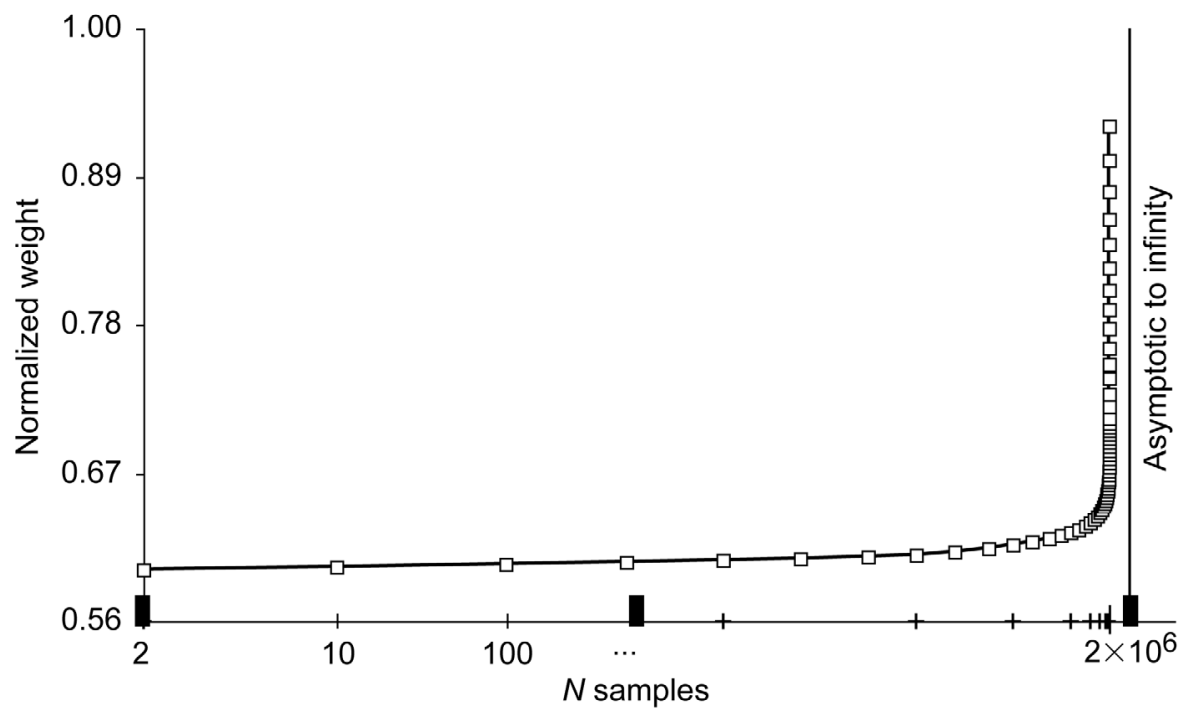

Figure 14.- Half of inverted-S-shaped graph for design model 1 and load case A. 

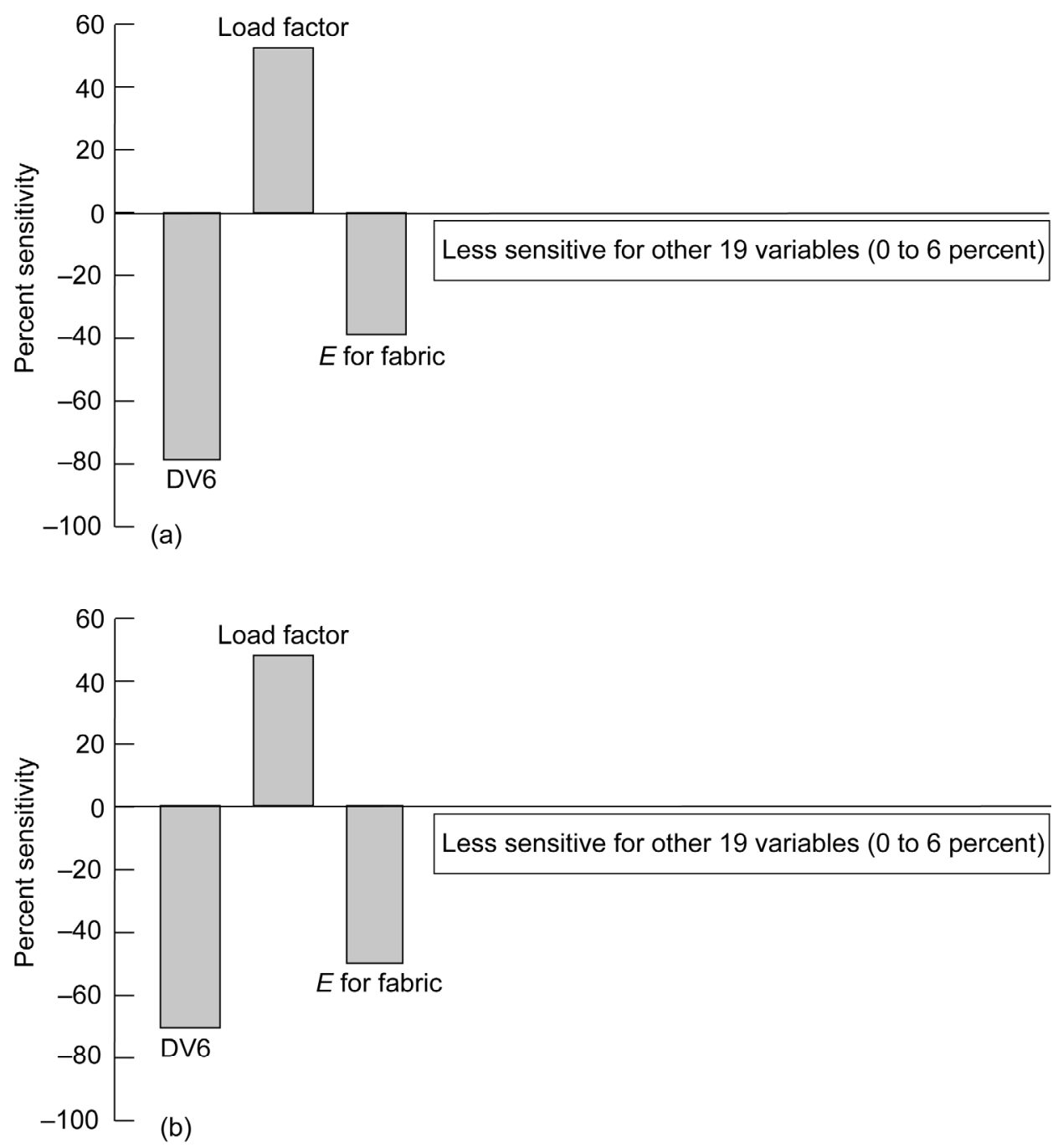

Figure 15.- Sensitivity analysis for principal strain in element 11531, where DV6 refers to design variable 6 and $E$ is elastic modulus. (a) Deterministic design optimization.

(b) Stochastic design optimization.

The element strain was most sensitive to load and elastic modulus $\mathrm{E}$ for fabric as well as for a particular design variable. Strain was not sensitive to other random variables. Both deterministic as well as stochastic methods identified the same set of variables, namely a design variable, load, and Young's modulus. The CPU time to solution is given in Table 5. The calculation used CometBoards, which is NASA in-house software, along with MSC/Nastran version 2005.5.0 (2005R3) and the FPI module of NESSUS level 6.2 code (1995). Calculations used a Red Hat Linux 2.6.9-67.ELsmp O/S, with x86_64 architecture, $2600 \mathrm{MHz}, 4 \mathrm{CPU}, 8 \mathrm{~GB}$ of memory, and 32-bit numeric format. One static analysis cycle required about $5 \mathrm{CPU} \mathrm{sec}$. The run time increased to $51 \mathrm{sec}$ for dynamic analysis. Stochastic analysis required about $47 \mathrm{~min}$. Deterministic optimization required about $39 \mathrm{~min}$. The CPU time for stochastic optimization was enormous at 126 to $128 \mathrm{hr}$ of continuous calculations. 


Activity

\section{Conclusions}

The multidisciplinary design optimization testbed COMparative Evaluation Testbed of Optimization and Analysis Routines for the Design of Structures (CometBoards) has been applied successfully to design structural systems, jet engines, and airliner synthesis problems. Its special features included multiple optimizer cascade algorithm, subproblem solution strategy, approximation of sensitivity, and neural network and regression approximations. The testbed has been extended into the stochastic domain. The testbed CometBoards with MSC/Nastran and a fast probability integrator successfully generated reliability-based design optimization for an industrial-strength problem. Stochastic optimization methodology requires probabilistic models for load, material properties, failure theory, and design parameters. Accuracy of the design solution depends on the models. Stochastic optimum weight versus reliability traced out an inverted-S-shaped graph. Weight increased when risk was reduced and vice versa. The design sensitivity can identify critical zones for redesign consideration. Both deterministic and stochastic concepts identified identical zones. There was no preference to either concept.

\section{References}

1. Patnaik, S.N.; and Hopkins, D.A.: General-Purpose Optimization Method for Multidisciplinary Design Application. Int. J. Advances Engrg. Software, vol. 31, 2000, pp. 57-63.

2. Patnaik, S.N., et al.: Cascade Optimization Strategy for Aircraft and Air-Breathing Propulsion System Concepts. AIAA JA, vol. 34, 1997, pp. 136-139.

3. Patnaik, S.N., et al.: Neural Network and Regression Approximations in High Speed Civil Transport Aircraft Design Optimization. AIAA J. Aircraft, vol. 35, 1998, pp. 839-850.

4. Gendy, A.S., et al.: Optimization of Space Station Components Using Code CometBoards. Comp. Meth. Applied Mechanics Engrg., vol. 129, 1996, pp. 133-149.

5. Patnaik, S.N., et al.: Lessons Learned During Solutions to Multidisciplinary Design Optimization Problems. AIAA JA, vol. 39, 2002, pp. 386-393.

6. Patnaik, S.N., et al.: Optimization for Aircraft Engines With Regression and Neural Network Analysis Approximators. AIAA J. Propulsion, vol. 35, 1998, pp. 839-850.

7. Guptill, J.D., et al.: Extension of Optimization Test Bed CometBoards to Probabilistic Design. 6th Annual FAA/Air Force/NASA/Navy Workshop on the Application of Probabilistic Methods to Gas Turbine Engines, Solomons Island, MD, 2003.

8. Wei, X.: Stochastic Analysis and Optimization of Structures. Ph.D. Dissertation, University of Akron, 2006.

9. Thacker, B.H., et al.: Probabilistic Engineering Analysis Using the NESSUS Software Structural Safety. Vol. 28, nos. 1-2, 2006, pp. 83-107.

10. Patnaik, S.N.; Guptill, J.D.; and Berke, L.: Singularity in Structural Optimization.

11. Int. J. Numer. Methods Eng., vol. 36, 1993, pp. 931-944.

12. Patnaik, S.N.; Coroneos, R.M.; and Hopkins, D.A.: A Cascade Optimization Strategy for Solution of Difficult Design Problems. Int. J. Numer. Methods Eng., vol. 40, 1997, pp. 2257-2266.

13. RPK_NASTRAN, COSMIC. University of Georgia, Athens, GA.

14. MSC/NASTRAN Quick Reference Guide, Version 68, MacNeal-Schwendler Corporation, 1992. 
15. Nakazawa, S.: MHOST Version 4.2. Vol. 1: User's Manual. NASA CR-182235-VOL-1, 1989.

16. Vance, V.; and Tischler, V.A.: ANALYZE-Analysis of Aerospace Structures With Membrane Elements. Report AFFDL-TR-78-170, 1978.

17. Patnaik, S.N.; Coroneos, R.M.; and Hopkins, D.A.: Dynamic Animation of Stress Modes Via the Integrated Force Method of Structural Analysis. Int. J. Numer. Methods Eng., vol. 40, 1997, pp. 2151-2169.

18. McCullers, L.A.: Aircraft Configuration Optimization Including Optimized Flight Profiles. J. NASA CP-2327, pt. 1, 1984.

19. Klann, J.L.; and Snyder, C.A.: NEPP Programmers Manual. NASA TM-106575, 1994.

20. ANSYS Inc. Ansys Release 9.0 Documentation, SAS IP Inc., 2004.

21. National Space Transportation System. NSTS-07700, ICD-2-19001, Rev. K.: Shuttle Orbit/Cargo Standard Interfaces, NASA Johnson Space Center, Houston, TX, 1991. 


\begin{tabular}{|c|c|c|}
\hline \multicolumn{2}{|c|}{ REPORT DOCUMENTATION PAGE } & $\begin{array}{l}\text { Form Approved } \\
\text { OMB No. 0704-0188 }\end{array}$ \\
\hline \multicolumn{3}{|c|}{ 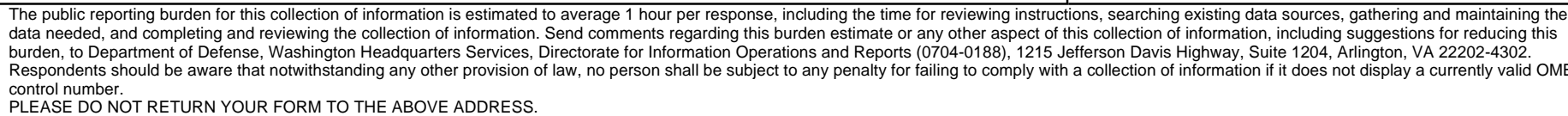 } \\
\hline $\begin{array}{l}\text { 1. REPORT DATE (DD-MM-YYYY) } \\
01-01-2010\end{array}$ & $\begin{array}{l}\text { 2. REPORT TYPE } \\
\text { Technical Memorandum }\end{array}$ & 3. DATES COVERED (From - To) \\
\hline \multirow{3}{*}{\multicolumn{2}{|c|}{$\begin{array}{l}\text { 4. TITLE AND SUBTITLE } \\
\text { Optimization Testbed CometBoards Extended Into Stochastic Dome }\end{array}$}} & 5a. CONTRACT NUMBER \\
\hline & & 5b. GRANT NUMBER \\
\hline & & 5c. PROGRAM ELEMENT NUMBER \\
\hline \multirow{3}{*}{\multicolumn{2}{|c|}{$\begin{array}{l}\text { 6. AUTHOR(S) } \\
\text { Patnaik, Surya, N.; Pai, Shantaram, S.; Coroneos, Rula, M. }\end{array}$}} & 5d. PROJECT NUMBER \\
\hline & & 5e. TASK NUMBER \\
\hline & & $\begin{array}{l}\text { 5f. WORK UNIT NUMBER } \\
\text { WBS 561581.02.08.03.13.05 }\end{array}$ \\
\hline \multicolumn{2}{|c|}{$\begin{array}{l}\text { 7. PERFORMING ORGANIZATION NAME(S) AND ADDRESS(ES) } \\
\text { National Aeronautics and Space Administration } \\
\text { John H. Glenn Research Center at Lewis Field } \\
\text { Cleveland, Ohio 44135-3191 }\end{array}$} & $\begin{array}{l}\text { 8. PERFORMING ORGANIZATION } \\
\text { REPORT NUMBER } \\
\text { E-17082 }\end{array}$ \\
\hline \multirow{2}{*}{\multicolumn{2}{|c|}{$\begin{array}{l}\text { 9. SPONSORING/MONITORING AGENCY NAME(S) AND ADDRESS(ES) } \\
\text { National Aeronautics and Space Administration } \\
\text { Washington, DC 20546-0001 }\end{array}$}} & $\begin{array}{l}\text { 10. SPONSORING/MONITOR'S } \\
\text { ACRONYM(S) } \\
\text { NASA }\end{array}$ \\
\hline & & $\begin{array}{l}\text { 11. SPONSORING/MONITORING } \\
\text { REPORT NUMBER } \\
\text { NASA/TM-2010-215820 }\end{array}$ \\
\hline \multicolumn{3}{|c|}{$\begin{array}{l}\text { 12. DISTRIBUTIONIAVAILABILITY STATEMENT } \\
\text { Unclassified-Unlimited } \\
\text { Subject Category: } 39 \\
\text { Available electronically at http://gltrs.grc.nasa.gov } \\
\text { This publication is available from the NASA Center for AeroSpace Information, 443-757-5802 }\end{array}$} \\
\hline
\end{tabular}

\section{SUPPLEMENTARY NOTES}

\section{ABSTRACT}

COMparative Evaluation Testbed of Optimization and Analysis Routines for the Design of Structures (CometBoards) is a multidisciplinary design optimization software. It was originally developed for deterministic calculation. It has now been extended into the stochastic domain for structural design problems. For deterministic problems, CometBoards is introduced through its subproblem solution strategy as well as the approximation concept in optimization. In the stochastic domain, a design is formulated as a function of the risk or reliability. Optimum solution including the weight of a structure, is also obtained as a function of reliability. Weight versus reliability traced out an inverted-Sshaped graph. The center of the graph corresponded to 50 percent probability of success, or one failure in two samples. A heavy design with weight approaching infinity could be produced for a near-zero rate of failure that corresponded to unity for reliability. Weight can be reduced to a small value for the most failure-prone design with a compromised reliability approaching zero. The stochastic design optimization (SDO) capability for an industrial problem was obtained by combining three codes: MSC/Nastran code was the deterministic analysis tool, fast probabilistic integrator, or the FPI module of the NESSUS software, was the probabilistic calculator, and CometBoards became the optimizer. The SDO capability requires a finite element structural model, a material model, a load model, and a design model. The stochastic optimization concept is illustrated considering an academic example and a real-life airframe component made of metallic and composite materials.

\section{SUBJECT TERMS}

Deterministic; Stochastic; Risk; Industrial problem; CometBoards; Distribution; Normal; Weibull; Strain energy; Inverted S-graph

\begin{tabular}{|l|l|l|l|c|l|}
\hline \multicolumn{2}{|l|}{ 16. SECURITY CLASSIFICATION OF: } & $\begin{array}{l}\text { 17. LIMITATION OF } \\
\text { ABSTRACT }\end{array}$ & $\begin{array}{l}\text { 18. NUMBER } \\
\text { OF } \\
\text { PAGES }\end{array}$ & $\begin{array}{l}\text { 19a. NAME OF RESPONSIBLE PERSON } \\
\text { STI Help Desk (email:help@sti.nasa.gov) }\end{array}$ \\
\cline { 1 - 2 } $\begin{array}{l}\text { a. REPORT } \\
\text { U }\end{array}$ & $\begin{array}{l}\text { b. ABSTRACT } \\
\text { U }\end{array}$ & $\begin{array}{l}\text { C. THIS } \\
\text { PAGE } \\
\text { U }\end{array}$ & UU & 26 & $\begin{array}{l}\text { 19b. TELEPHONE NUMBER (include area code) } \\
\text { 4t43-757-5802 }\end{array}$ \\
\hline
\end{tabular}



